\title{
Teilnehmerhaftung bei fehlerhafter Kapitalmarktinformation in Deutschland und den USA
}

\author{
Zugleich ein Beitrag zur Systematik des § 830 Abs. 1 S. 1, Abs. 2 BGB
}

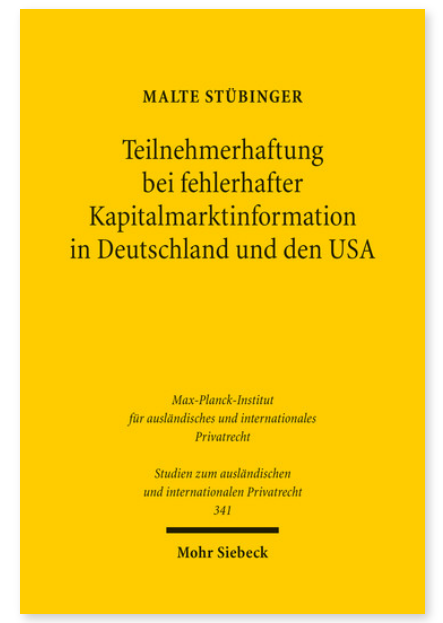

2015. XXVII, 408 Seiten. StudIPR 341

ISBN 978-3-16-153939-8

DOI 10.1628/978-3-16-153939-8

eBook PDF 89,00€

ISBN 978-3-16-153896-4

fadengeheftete Broschur $89,00 €$
Wer haftet Kapitalanlegern, wenn aufgrund von fehlerhafter Marktinformation Kursverfälschungen und Vermögensschäden eintreten? In Deutschland betritt terra incognita, wer nach der Haftungssituation der Berater des Emittenten fragt, die an relevanter Fehlinformation in zurechenbarer Weise mitgewirkt haben, während die Voraussetzungen der Inanspruchnahme von emittierenden Gesellschaften und deren Geschäftsleitern am Primär- wie auch am Sekundärmarkt weitgehend als erschlossen gelten dürfen.

In den USA hat der Supreme Court seit 1994 in mehreren landmark cases die einst anerkannte Teilnehmerhaftung weit zurückgedrängt und so sichere Häfen für Berater geschaffen, was ihm neben Lob auch viel Tadel einbrachte. Malte Stübinger vergleicht und bewertet die Lage im deutschen und US-amerikanischen Recht und erforscht insbesondere, unter welchen Voraussetzungen eine Verbindung der allgemeinen Teilnehmerhaftung des § 830 BGB mit den spezialgesetzlichen Haftungstatbeständen des Kapitalmarktdeliktsrechts statthaft ist.

Malte Stübinger Geboren 1986; Studium der Rechtswissenschaft an der Universität Hamburg; 2009-15 Mitarbeiter am Max Planck Institut für ausländisches und internationales Privatrecht, Hamburg; Forschungsaufenthalte an der University of Cambridge, UK (Wolfson College), in Breslau (PL) und Valencia (ESP); Lehraufträge an der Universität Hamburg und an der China University of Political Science and Law, Peking (CHN); 2013-15 Rechtsreferendar am Hanseatischen OLG, Hamburg.

Jetzt bestellen:

https://mohrsiebeck.com/buch/teilnehmerhaftung-bei-fehlerhafter-kapitalmarktinformation-in-deutschland-und-den-usa9783161539398?no_cache=1

order@mohrsiebeck.com

Telefon: +49 (0)7071-923-17

Telefax: +49 (0)7071-51104 